\title{
The Regional Impact Of Recent Inflation By Income Class \#
}

\author{
John S. Akin * and Stanley P. Stephenson, JR.**
}

Since 1972 the U.S.A. has experienced a rate of inflation well above any other in recent history. Annual inflation rates jumped from an average of about $4 \frac{1}{2}$ percent for the five years from 1967 to 1975 to an average rate of about 9 percent during the period from 1972 to 1975. This large increase in the rate of inflation has been noted, cursed, discussed and derided by speakers from all sections of the citizenry. Little agreement has been reached, however, as to which groups in society have been most affected by the mammoth price increases. This paper will present evidence that the ill effects of price increases have been felt to differing degrees across both income classes and regions of the country. Underlying the 67 percent increase in the Consumer Price Index between 1967 and 1975 are interesting patterns of regional effects by income class.

The Consumer Price Index is based on the Consumer Expenditures Survey done by the Bureau of Labor Statistics in 1961. To derive the CPI the BLS weights price changes by the percentages of income spent on various consumption items by urban wage earners and clerical workers. This "typical family" expenditure pattern is the basis for a market basket of items which is priced periodically in order to determine the cost of living in the U. S. Because the prices of different goods and services do not rise uniformly and because consumer units of different income levels, family makeups, and geographical locations purchase different mixes of goods and services, the CPI may be a poor indication of the effects of price increases experienced by actual families. Separate indexes are needed to capture the differential impacts due to the different bundles purchased over the nation and across income classes, as well as to the differing patterns of price changes over time in the different regions.

In this paper, therefore, we create twelve separate cost-of-living indexes on the basis of three income classes (poor, middle, and rich) in the four major regions of the country (Northeast, North Central, South and West). After estimating from the Consumer Expenditure Survey the percents of after-tax income spent on various goods and services in the regions, we use the price change series for the regions, as published by

\footnotetext{
\#This paper was prepared for presentation at the Western Economic Association Meetings, San

Francisco, June 1976. We acknowledge the help received from discussions with Larry Orr.

*University of North Carolina and Brookings Economic Policy Fellow at DHEW.

**:Pennsylvania State University and Brookings Economic Policy Fellow at DHEW.
} 
the Bureau of Labor Statistics," to determine changes in the cost of the twelve specific market baskets over the period of inflation. The results of this exercise in the construction of Laspeyres price indexes allow us to determine the relative price indexes experienced by families in various parts of the country, given the assumption that the mix of goods and services purchased by each group does not change over the period of analysis.

For our analysis we have chosen urban families of four, consisting of a male adult, a female adult and two children. We have chosen to analyze urban families to avoid the problem of odd rural expenditure patterns as a result of food raised at home. Our choice of families of four is an attempt to choose that family type on which most discussions of the poverty level are centered. We define these families of four in 1961 as poor if their after-tax income is less than $\$ 3000$, as middle class if income is between our poor cutoff and $\$ 10,000$, and as rich if they earn after-tax income exceeding $\$ 10,000$.

The results in Table 1 indicate that the poor spend a much greater percentage of their income on housing and food than do the rich in every region of the U. S. Only in the South do the poor spend less than 65 percent of after-tax income on the sum of these two classes of necessities. The total U. S. average for these categories, by comparison, is only 51 percent. On the basis of these results food and housing can be categorized as necessities, because of decreasing percentages of income spent on them as family income increases, but the other groups of items follow no such consistent patterns across the regions. In the South the percentage of income spent on transportation tends to decrease for higher income classes, but in the other three regions those in the middle income class spend the greatest percentage on travel. The poor spend relatively small percentages on health and recreation in the Northeast and North Central area, but those in that income class in the South and West spend relatively larger amounts.

Having seen documentation in Table 1 of the differences in expenditure patterns, both across income classes and across regions, we need also examine the second set of relevant information for our price index construction: price changes by region for the items in the consumption bundle. In Table 2 the 1975 prices of the classes of expenditures are presented. Because 1967 is used as the base year, the magnitude of each price indicates the degree of increase since 1967. No index is presented on the miscellaneous category "other" because prices for this set of items (mainly consisting of alcohol and tobacco) are not published for the regions. We see that over the whole U. S. the Consumer Price Index has increased 61.2 percent, while food has gone up 75.4 percent, housing 66.8 percent, health and recreation 53.5 percent, transportation 50.5 percent and apparel a relatively small 42.3 percent. In the Northeast every category has increased in price to a greater extent than the U. S. average

\footnotetext{
*Handbook of Labor Statistics, 1975.
} 
TABLE 1

Expenditures by Consumption Class*

(Percent of After-tax Income)

U. S. A.

\begin{tabular}{|c|c|c|c|c|}
\hline & All & Poor & Middle & Rich \\
\hline Food $(\mathrm{F})$ & 23.7 & 33.0 & 24.7 & 17.7 \\
\hline Housing $(\mathrm{H})$ & 27.1 & 34.0 & 27.9 & 22.5 \\
\hline Apparel (A) & 10.2 & 9.0 & 10.2 & 10.0 \\
\hline Transportation $(\mathbf{T})$ & 13.8 & 16.3 & 14.0 & 12.7 \\
\hline Health \& Recreation (HR) & 16.5 & 15.3 & 16.4 & 16.6 \\
\hline Other $(\mathrm{O})$ & 2.9 & 4.3 & 3.1 & 2.6 \\
\hline \multirow[t]{2}{*}{ Total ( ) } & 94.2 & 111.9 & 96.3 & 82.1 \\
\hline & \multicolumn{2}{|c|}{ Northeast } & & \\
\hline $\mathbf{F}$ & 26.2 & 37.9 & 27.4 & 19.9 \\
\hline $\mathrm{H}$ & 27.4 & 30.9 & 28.3 & 23.5 \\
\hline A & 10.8 & 8.3 & 10.8 & 10.8 \\
\hline $\mathrm{T}$ & 12.5 & 10.9 & 12.7 & 11.7 \\
\hline $\mathrm{HR}$ & 15.6 & 15.0 & 15.3 & 17.0 \\
\hline \multirow[t]{3}{*}{$\mathrm{O}$} & 3.6 & 3.6 & 3.7 & 3.6 \\
\hline & 96.1 & 106.6 & 98.2 & 86.5 \\
\hline & \multicolumn{2}{|c|}{ North Central } & & \\
\hline $\mathrm{F}$ & 22.7 & 31.2 & 23.7 & 16.3 \\
\hline $\mathrm{H}$ & 27.2 & 40.5 & 27.9 & 21.6 \\
\hline A & 9.9 & 7.5 & 9.9 & 10.5 \\
\hline $\mathrm{T}$ & 13.9 & 9.9 & 14.1 & 13.2 \\
\hline HR & 16.3 & 13.5 & 16.3 & 15.8 \\
\hline \multirow[t]{3}{*}{$\mathrm{O}$} & 2.9 & 5.6 & 3.0 & 2.3 \\
\hline & 92.9 & 108.6 & 94.9 & 79.7 \\
\hline & \multicolumn{2}{|c|}{ South } & & \\
\hline $\mathrm{F}$ & 22.6 & 31.6 & 23.1 & 16.4 \\
\hline $\mathrm{H}$ & 26.5 & 30.0 & 26.7 & 24.1 \\
\hline A & 10.4 & 11.0 & 10.5 & 9.9 \\
\hline $\mathrm{T}$ & 14.9 & 25.6 & 14.9 & 12.9 \\
\hline HR & 17.2 & 17.0 & 17.1 & 16.7 \\
\hline \multirow[t]{3}{*}{$\mathrm{O}$} & 2.7 & 3.4 & 2.8 & .2 .3 \\
\hline & 94.3 & 118.6 & 95.1 & 82.3 \\
\hline & \multicolumn{2}{|c|}{ West } & & \\
\hline $\mathrm{F}$ & 22.4 & 26.8 & 23.9 & 17.0 \\
\hline $\mathrm{H}$ & 27.2 & 46.2 & 28.9 & 21.2 \\
\hline A & 9.3 & 7.7 & 9.6 & 8.2 \\
\hline $\mathbf{T}$ & 14.7 & 11.0 & 15.0 & 13.5 \\
\hline HR & 17.2 & 28.0 & 17.5 & 16.2 \\
\hline \multirow[t]{2}{*}{$\mathrm{O}$} & 2.5 & 3.8 & 2.5 & 2.3 \\
\hline & 93.3 & 123.5 & 97.4 & 78.4 \\
\hline
\end{tabular}

*Source: U. S. Department of Labor, Bureau of Labor Statistics, Survey of Consumer Expenditures, 1960-61. 
TABLE 2

Price Indexes for Consumer Items, 1975

$(1967=100)$

\begin{tabular}{lccccc}
\hline & U. S. & N. E. & N. C. & S. & W. \\
\hline Total (CPI) & 161.2 & 164.0 & 158.5 & 163.7 & 157.7 \\
Food & 175.4 & 177.0 & 173.3 & 178.7 & 169.9 \\
Housing & 166.8 & 170.3 & 160.0 & 171.8 & 165.5 \\
Apparel & 142.3 & 143.0 & 142.2 & 144.0 & 139.2 \\
Transportation & 150.6 & 154.6 & 149.3 & 149.2 & 148.6 \\
Health \& Recreation & 153.5 & 155.8 & 154.1 & 154.7 & 147.1
\end{tabular}

*Source: U. S. Department of Labor, Bureau of Labor Statistics, Handbook of Labor Statistics, 1975.

while in the West every category experienced smaller than U. S. average price increases. In the North Central area 5 of the 6 categories had smaller than average price increases, while 5 of the 6 increased greater than the average amount in the South. The CPI (based•on a "typical" family's budget) went up most in the N. E. and least in the West. Increases in the CPI bundle were almost as great in the South, however, and food, housing and apparel prices all had larger increases in the South than in any other region.

Having now noted both the differences in price increases by class of consumption items and by region, and the differences in expenditure patterns of consumers by income class and by region we can appreciate the necessity for a device such as a consumer price index to aid us in abstracting all this information down to an easily digestible summary. In Table 3 are presented poor price indexes (PPIs) middle income price indexes (MPIs) rich price indexes (RPIs), and total price indexes for our families of four over the whole U. S. and in each region. Each index provides us with one easily interpreted number - the cost at prevailing prices in the year of interest of the 1961 bundle purchased by the given income groups in the specific geographic location. From this Table we can determine that a poor family in the N. E. in 1975 must pay $\$ 1.67$ for the quantity of goods $\$ 1.00$ purchased in 1967 (we are implicitly assuming here that each dollar spent is divided among the types of consumer items in exactly the same pattern as in 1961). We can suggest that a family which spent its total after-tax income of $\$ 3000$ in the N. E. in 1967 must spend $\$ 5001$ in 1975 to purchase exactly the same set of goods and services. For the rich family which earned more than $\$ 10,000$ in 1967 each $\$ 3000$ spent at that period can be matched in purchasing power of goods and services by $\$ 4896$ in 1975 . Because of the difference in the items purchased, the hypothetical poor family has seen each 1967 dollar's purchasing power shrink to approximately $60 \phi$ in 1975 while that of the rich family has fallen only to 61.3\%. Stated differently, if the poor and rich family in the N. E. each spend three thousand 1975 dollars in the same consumption patterns they followed in 1961, they will be able to 
TABLE 3

Price Indexes

U. S. A.

\begin{tabular}{|c|c|c|c|c|}
\hline & All & Poor & Middle & Rich \\
\hline 1968 & 104.2 & 104.1 & 104.2 & 104.2 \\
\hline 1972 & 125.0 & 125.0 & 125.0 & 124.9 \\
\hline 1973 & 133.1 & 133.7 & 133.1 & 132.5 \\
\hline 1974 & 147.7 & 148.9 & 147.9 & 146.7 \\
\hline 1975 & 161.0 & 162.4 & 161.2 & 159.9 \\
\hline \multicolumn{5}{|c|}{ Northeast } \\
\hline 1968 & 104.2 & 104.1 & 104.1 & 104.2 \\
\hline 1972 & 128.3 & 128.3 & 128.3 & 128.3 \\
\hline 1973 & 136.9 & 138.1 & 137.0 & 136.4 \\
\hline 1974 & 152.2 & 154.2 & 152.4 & 151.1 \\
\hline 1975 & 164.4 & 169.6 & 166.7 & 163.2 \\
\hline \multicolumn{5}{|c|}{ North Central } \\
\hline 1968 & 104.3 & 104.2 & 104.3 & 104.4 \\
\hline 1972 & 123.9 & 124.2 & 123.9 & 123.8 \\
\hline 1973 & 131.8 & 132.8 & 131.8 & 131.1 \\
\hline 1974 & 146.1 & 147.7 & 146.2 & 145.0 \\
\hline 1975 & 158.7 & 160.8 & 158.8 & 157.4 \\
\hline \multicolumn{5}{|c|}{ South } \\
\hline 1968 & 104.3 & 104.1 & 104.3 & 104.3 \\
\hline 1972 & 124.4 & 123.7 & 124.4 & 124.5 \\
\hline 1973 & 132.9 & 132.5 & 132.9 & 132.4 \\
\hline 1974 & 149.0 & 149.1 & 149.1 & 148.2 \\
\hline 1975 & 163.5 & 163.5 & 163.6 & 162.6 \\
\hline \multicolumn{5}{|c|}{ West } \\
\hline 1968 & 103.6 & 103.7 & 103.6 & 103.6 \\
\hline 1972 & 121.7 & 122.5 & 121.8 & 121.5 \\
\hline 1973 & 129.3 & 130.0 & 129.4 & 128.8 \\
\hline 1974 & 143.2 & 143.8 & 143.4 & 142.4 \\
\hline 1975 & 157.7 & 158.9 & 157.9 & 156.8 \\
\hline
\end{tabular}

purchase the amounts of goods they could have purchased for $\$ 1799.64$ and $\$ 1838.24$ respectively in 1961 . Other similar comparisons can be made.

Some general patterns can be deciphered from the results. As a result of both expenditure patterns and price changes the regions have fared quite differently during the years of high inflation. Since 1967 the Northeast has seen its cost of living increase to the greatest extent $(64.4 \%$ for the average family of 4 ) while that of the South has risen almost as much $(63.5 \%)$, and those of the N. C. area $(58.7 \%)$ and the West $(57.7 \%)$ have risen six to seven fewer percentage points. The message of the numbers does not end with these regional comparisons, however. We note that the poor have fared worse than the middle income and rich 
families in three of the four regions." It seems that those least able to withstand loss of purchasing power have been hardest hit in percentage terms.**

If we order all subpopulations on the basis of the extent to which the price of the 1967 bundle has increased we come up with the following:

$\begin{array}{ll}\text { Largest increase: } & \text { N. E. poor } \\ & \text { N. E. middle } \\ & \text { S. middle } \\ \text { S. poor } & \text { N. E. rich } \\ & \text { S. rich } \\ \text { N. C. poor } & \text { W. poor } \\ \text { N. C. middle } & \text { W. middle } \\ & \text { N. C. rich } \\ \text { Smallest increase: } & \text { W. rich }\end{array}$

This ordering sufficiently illustrates the uneven impact of the present cycle of inflation across the nation and across income classes. What it cannot indicate is the unfortunate fact that the group indicated as relatively most fortunate has experienced an increase in its cost of living of 57\% between 1967 and 1975. Even the winners and losers in such an inflationary period.

This first attempt to provide price indexes differentiated by both income levels and region provides strong evidence that such disaggregation is called for if the extent to which price increases affect the various groups in society is to be understood.*** While poor, middle and rich price indexes for the total U. S. leads to the conclusion that on average the normal mix of goods purchased by the poor has risen by only 2.7 more percentage points than that of the rich. From the regional price indexes, however, we can determine that the inflationary years since 1967 have increased the costs of the Northeastern poor by approximately 10 percentage points more than those of the Western rich.**** Such gaps as those indicate vividly the extent to which changing price levels can differ-

\footnotetext{
*In the South the poor and middle have suffered about equally while the rich have experienced a slightly small increase in the cost of living.

**k It should also be remembered that a given percentage decrease in purchasing power may harm the poor more than others because of their small absolute incomes. For those who are unable or barely able to purchase many of the necessities of life a severe cut in real income is almost without doubt more serious than an equal percentage loss for those who are many thousands of dollars above the subsistence level.

***A note of warning should be appended to this paper. The price indexes only represent changes in the cost of bundles within regions. It is not possible to compare the absolute costs of goods and services in the regions. It is entirely possible that the absolute price level is highest in the West even though the rate of increase since 1967 has been lowest in this region. The available data only allows for comparison of changes within a given region and no across-region comparisons of absolute price levels are possible.

****Hollister and Palmer (1972) and Mirer (1974) have calculated price indexes for different income classes, but no previous attempt has been made to determine how price changes affect families at different income levels in different regions of the country.
} 
ently affect different groups in society. This increase in disaggregation also provides empirical evidence for a fairly obvious hypothesis. The extent to which different impacts can be documented is increased directly with the level of disaggregation of the population. To accept U. S. average results by income class as evidence of the disproportionate impacts on income classes of price changes is to be left unaware of the extent to which the poor in some parts of the country have been affected relative to other groups.

\section{REFERENCES}

1. Hollister, Robinson G. and John L. Palmer, "The Impact of Inflation on the Poor and the Implicit Tax of Inflation and Unemployment: Some Policy Implications," Redistribution to the Rich and the Poor: The Grants Economics of Income Distribution, Kenneth E. Boulding and Martin Pfaff, Editors, Belmont, California, Wadsworth, 1972.

2. Mirer, Thad, "The Distributional Impact of Inflation and Anti-Inflationary Policy," Institute for Research on Poverty Discussion Paper, No. 231, Madison, Wisconsin, 1974.

3. Sherwood, Mark K., "Family Budgets and Geographic Differences in Price Levels," Monthly Labor Review, Vol. 98, No. 4, April, 1975.
4. Smeeding, Timothy M., "Cost of Living Differentials at Low-Income Levels," Institute for Research on Poverty Discussion Paper \#190, Madison, Wisconsin, 1974.

5. U. S. Department of Labor, Bureau of Labor Statistics, Handbook of Labor Statistics, 1975, Washington, U. S. Government Printing Office, 1975.

6. Tape, 1964.

7. Watts, Harold, "The Iso-Prop Index: An Approach to the Determination of Differential Poverty Income Thresholds," Journal of Human Resources, Vol. 2, No. 1, Winter, 1967. 